\title{
Mixed Convection in a Square Cavity Filled with Porous Medium with Heated Bottom Wall
}

\author{
Prof. Ihsan Y. Hussein,Ph.D \\ Mechanical Eng. Dept. \\ University of Baghdad \\ Iraq-Baghdad
}

\author{
Luma F. Ali \\ Mechanical Eng. Dept. \\ University of Baghdad \\ Iraq-Baghdad
}

\begin{abstract}
Two-dimensional unsteady mixed convection in a porous cavity with heated bottom wall is numerically studied in the present paper. The forced flow conditions are imposed by providing a hydrostatic pressure head at the inlet port that is located at the bottom of one of the vertical side walls and an open vent at the top of the other vertical side wall. The Darcy model is adopted to model the fluid flow in the porous medium and the combination effects of hydrostatic pressure head and the heat flux quantity parameters are carefully investigated. These governing parameters are varied over wide ranges and their effect on the heat transfer characteristics is studied in detail. It is found that the time required to reach a desired temperature at the bottom wall decreases with heat flux and pressure head increase. The higher heat flux quantities leaves wider regions near the top wall at lower temperatures which is important in most engineering applications like drying.
\end{abstract}

\section{Keywords}

Porous Medium, Mixed Convection, Square Cavity, Uniform Heating, Finite Volume Method.

\section{INTRODUCTION}

The involvement of both natural and forced convection, referred as mixed convection, in porous media has been an important topic because of its wide range of applications in engineering and science. Some of these applications include oil extraction, cooling of electronic devices and heat transfer improvement in heat exchanger devices. The interaction mechanisms between the buoyancy-induced flows and forced convection was given very little attention whereas early studies on convection in porous media were largely devoted to buoyancy-induced flows and forced convection. Initial research on mixed convection was motivated to provide a fundemeantal understanding of the upward convective drift of subsurface ground water due to buoyancy caused by high temperatures in the geothermal region of Wairakei, New Zealand [1\&2]. Mainly, the problems of mixed convection in confined porous medium can be classified into two categories, first the type of moving lid cavities filled with porous medium with different boundary conditions while the second category involves mixed convection resulted from exit ports, vented openings, open cavities, or vibration effects.

The problem of mixed convective flow and heat transfer in a top lid driven enclosure filled with a Darcian fluid-saturated porous medium with internal heat generation was analyzed by Khanafer and Chamkha [3]. Al-Amiri [4] and Kandaswamy et. al. [5] scrutinized numerically the laminar transport in a lid-driven two-dimensional fluid-saturated porous medium square cavity with top wall moving and kept at a constant temperature higher than that of the bottom. Furthermore, the influence of the buoyancy ratio, Lewis number, Reynolds number, and Darcy number on heat and mass transfer processes in double-diffusive mixed convection in a top lid driven enclosure filled with a non-Darcian saturated porous medium was analyzed by Khanafer and Vafai [6]. Later, Oztop [7] analyzed numerically the effect of the position of a heater with finite length on the fixed wall in a partially heated porous top lid driven square enclosure on the combined heat transfer field and fluid flow. The lattice Boltzmann method was used by Chai et. al. [8] in order to simulate the mixed convection in a top lid-driven square cavity packed with homogeneous and isotropic porous medium. The steady and unsteady mixed convection flow in a square enclosure filled with a fluid-saturated uniform porous medium with two vertical walls moving upward and upward and downward was investigated respectively by Vishnuvardhanarao and Das [9] and Kumar et. al. [10]. Afterwards, Muthtamilselvan et. al. [11] examined numerically convection in a two-sided liddriven heat generating porous cavity with alternative thermal boundary conditions. While, steady mixed convection flow in a two-dimensional square cavity filled with a non-Darcy fluid saturated porous medium with internal heat generation was investigated numerically by Kumari and Nath [12] using the penalty finite element method. Waheed et. al. [13] conducted numerically the buoyancy and shear-driven flow induced by a hot plate moving through the horizontal mid-plane of a rectangular enclosure filled with fluid-saturated porous medium. Finally, Oztop [14] analyzed numerically the effects of buoyancy-aiding or buoyancy-opposing mechanisms on laminar mixed convection heat transfer in a porous enclosure partially cooled from the left vertical wall for two different forms of thermal boundary conditions in steady state regime using the Darcy-Brinkman-Forchheimer equation model.

For the second category of mixed convection, Mahmud and Pop [15], Ghazanfarian and Abbassi [16], and Bhuiyan et. al. [17] examined numerically the steady laminar mixed convection flow in a square vented cavity filled with a fluidsaturated porous medium. The transformed equations of Darcy and energy in non-dimensional form had been solved by utilizing different numerical methods, and the variation of Rayleigh number, Peclet number, and the width of the inlet as a fraction of the enclosure height over wide ranges were studied in detail. While, Chung and Vafai [18] constituted the first study of vibration and buoyancy induced mixed convection in an open-ended obstructed cavity filled with a fluid-saturated porous medium. They discussed the variation effect of the vibrational Reynolds, modified Rayleigh, and Darcy numbers on streamlines, isotherms, the average Nusselt number and additionally the variation effects of Prandtl 
number and dimensionless frequency of the vertical vibrational velocity were also examined. The influence of multiple injection/suction at bottom/top walls on non-Darcy mixed convection flow in a vertical square enclosure filled with fluid-saturated porous medium was studied computationally using finite element method by Kumar and Murthy [19]. They carried out detailed numerical solutions for a wide range of parameters such as Grashof number, Rayleigh number, injection/suction velocity, and injection/suction window width.

In the present study, transient mixed convection in a twodimensional square cavity subjected to hydrostatic pressure head and filled with a Darcian fluid-saturated porous medium is investigated numerically. The two vertical walls of the confined porous medium are insulated while the bottom wall is heated uniformly and the heat is lost by convection from the top wall which is exposed to the environment. Detailed numerical solutions are carried out by utilizing the finite volume method for a range of parameters, namely the pressure head and the amount of the uniform heating. Numerical results are obtained for pressure, velocity and temperature fields within the enclosure and are displayed using pressure contours, velocity vector plot and isotherms respectively.

\section{MATHEMATICAL FORMULATION}

The two-dimensional inclined cavity under investigation is filled with fluid-saturated porous medium and all the walls are impermeable except the upper wall. Glass beads with specified diameter is used as a porous media and distilled water is used as the incompressible fluid that saturates the porous medium. The schematic configuration of the problem is illustrated in Fig. 1, with $L$ denoting the length of the square cavity. Furthermore, the porous medium is assumed to be in local thermal equilibrium with the fluid.

The two vertical left and right sidewalls are adiabatic, and a uniform heating is applied on the bottom wall while the top wall is exposed to the environment and losses heat by natural convection. Water is supplied to the cavity from an external tank with a static head from an opening inlet at the bottom left corner and there is a water outlet open at the upper right corner. The thermophysical properties of the fluid and the porous material are taken to be constant except for the density variation in the buoyancy force, which is treated by the Boussinesq approximation.

The Darcy equation formulation is adopted for modeling the fluid flow in the porous medium. The governing equations for mass, momentum, and energy in two-dimensional, Cartesian coordinates, laminar flow are as follows:

\section{Continuity equation}

$\frac{\partial u}{\partial x}+\frac{\partial v}{\partial y}=0$

Momentum equation

$$
\begin{aligned}
& u=-\frac{K}{\mu_{f}}\left[\frac{\partial p}{\partial x}+\rho_{f} g \sin \varphi\right] \\
& v=-\frac{K}{\mu_{f}}\left[\frac{\partial p}{\partial y}+\rho_{f} g \cos \varphi\right]
\end{aligned}
$$

Energy equation

$\sigma \frac{\partial T}{\partial t}+\left[u \frac{\partial T}{\partial x}+v \frac{\partial T}{\partial y}\right]=\frac{k_{e f f}}{\left(\rho C_{p}\right)_{f}}\left[\frac{\partial^{2} T}{\partial x^{2}}+\frac{\partial^{2} T}{\partial y^{2}}\right]$

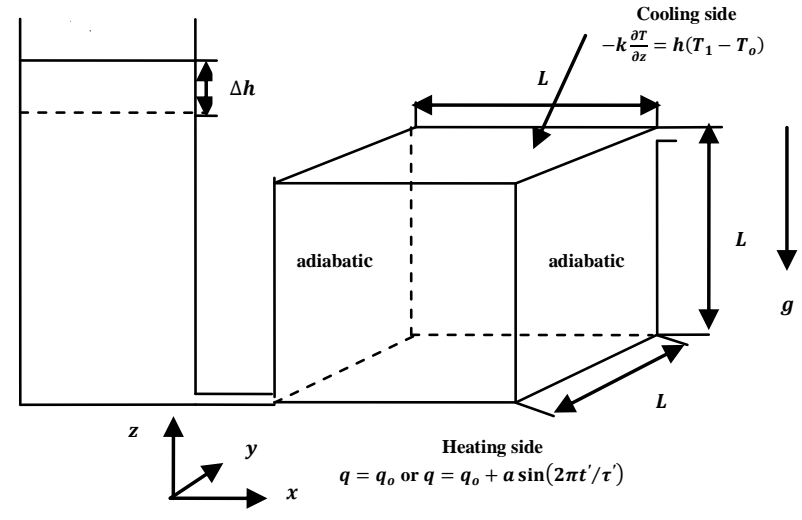

Figure (1): Schematic Diagram of the Physical Problem and Coordinates System.

where $u$ and $v$ are the fluid velocities in $x$ and $y$ directions respectively, $K$ is the porous medium permeability, $\mu_{f}$ is the fluid dynamic viscosity, $p$ is fluid pressure, $\rho_{f}$ is the fluid density, $g$ is the acceleration due to gravity, $\varphi$ is the inclination angle of the cavity, $T$ is the fluid temperature, $t$ is the time, and $\sigma$ is the specific heat ratio which is given as:

$\sigma=\frac{\left(\rho C_{p}\right)_{m}}{\left(\rho C_{p}\right)_{f}}$

where $C_{p}$ is the specific heat at constant pressure and the subscripts $m$ and $f$ denoted to effective value and fluid phase respectively, $k_{e f f}$ is effective thermal conductivity of porous medium and it is given by [20]:

$\frac{k_{e f f}}{k_{f}}=\left(1-\alpha_{o}\right) \frac{\varepsilon f_{o}+\lambda\left(1-\varepsilon f_{o}\right)}{1-\varepsilon\left(1-f_{o}\right)+\lambda \varepsilon\left(1-f_{o}\right)}+\alpha_{o} \frac{2 \lambda^{2}(1-\varepsilon)+(1+2 \varepsilon) \lambda}{(2+\varepsilon) \lambda+1-\varepsilon}$

where $\varepsilon$ is the porosity of the porous medium and $k_{s}$ and $k_{f}$ are the thermal conductivity of the solid material and fluid phase of the porous medium respectively, $\lambda=k_{s} / k_{f}$ is the thermal conductivity ratio of solid and liquid phases, $f_{o}$ is a parameter which is expected to be approximately constant for a contiguous solid, and $\alpha_{o}$ is an another parameter that is very sensitive to porosity changes and it is represented for different porosity ranges as [21]:

$$
\begin{array}{cc}
\log \alpha_{o}=-4.898 \varepsilon & 0 \leq \varepsilon \leq 0.0827 \\
\log \alpha_{o}=-0.405-3.154(\varepsilon-0.0827) \\
0.0827 \leq \varepsilon \leq 0.298 \\
\log \alpha_{o}=-1.084-6.778(\varepsilon-0.298) \\
0.298 \leq \varepsilon \leq 0.58
\end{array}
$$

The equation of state under the Boussinesq approximation is assumed to be:

$\rho=\rho_{o}\left[1-\beta\left(T-T_{o}\right)\right]$

where $\rho_{o}$ and $T_{o}$ are respectively the density and the temperature in the reference state, $\beta$ the coefficient of thermal expansion.

In accordance with the present problem, the above governing equations are subjected to the following initial and boundary conditions: 
$u=v=0, T=T_{o} \quad$ at $t=0$

$u=v=0, \frac{\partial T}{\partial x}=0 \quad$ at $x=0$ and $x=L$

$u=0, k_{e f f} \frac{\partial T}{\partial y}=q, p=\rho g(L+\Delta h) \quad$ at $\quad y=0$

$u=0, k_{\text {eff }} \frac{\partial T}{\partial y}=h\left(T-T_{o}\right), p=0 \quad$ at $\quad y=L$

where $q$ is the uniform heat flux, $h$ is the natural heat convection coefficient.

After inserting the Boussinesq approximation in the momentum equations (2) and (3), and the resulting equations substituted in equation (1), the following new pressure differential equation is obtained:

$\frac{\partial^{2} p}{\partial x^{2}}+\frac{\partial^{2} p}{\partial y^{2}}=g \rho_{o} \beta\left[\sin \varphi \frac{\partial T}{\partial x}+\cos \varphi \frac{\partial T}{\partial y}\right]$

Equations (4) and (13) are solved numerically with the applied initial and boundary conditions to simulate the mixed convection in the inclined square cavity. The average Nusselt number on the bottom hot wall is given as:

$N u=\frac{\int_{0}^{L} \frac{\partial T}{\partial y} d x}{\left(T_{b}-T_{o}\right)}$

where $T_{b}$ is the boom hot wall temperature

\section{NUMERICAL FORMULATION}

The governing equations (4) and (13) in the present problem of mixed convection in a cavity filled with porous medium are solved by using the finite volume method [22]. A fully implicit scheme is applied for discretizing the time derivatives. The convective fluxes at the cell interface are discretized by employing the Quadratic Upwind Interpolation for Convective Kinematics (QUICK) scheme and a secondorder central difference scheme is used for the diffusion terms. The resulting algebraic equations are solved by the tridiagonal matrix algorithm (TDMA). For convergence criteria, the relative variations of the temperature and pressure between two successive iterations are demanded to be smaller than the previously specified accuracy levels of $10^{-5}$. The iterative procedure is initiated by the solution of the pressure equation followed by calculating the velocity field and then solving the energy equation until reaching a specific temperature. This specified temperature is the mean value of selected location temperatures near the bottom heated wall. In the present study, the desired temperature is taken as $90{ }^{\circ} \mathrm{C}$ which is the temperature at which the working water fluid changes to the two phase condition.

\section{CODE VALIDATION AND GRID INDEPENDENCY TEST}

Before proceeding further, the grid independency tests are performed first. Numerical experiments were performed for various grid sizes viz. $12 \times 12,16 \times 16,20 \times 20,24 \times 24$, $28 \times 28$, and $32 \times 32$ to test and estimate the grid independent solutions. These numerical experiments were accomplished for a hydrostatic head $\Delta h=10 \mathrm{~mm}$ and constant heat flux $q=100 \mathrm{~W} / \mathrm{m}^{2}$. It is observed that the average Nusselt number values at the bottom heated wall of the enclosure are very near to each other when the grid size is near $24 \times 24$. Therefore, a grid size of $24 \times 24$ is chosen for further computations because it consumed less computing time. The parameters of convergence are fixed to $10^{-5}$ for both pressure and temperature. Furthermore, a similar test was done for the time step value and it is found that $\Delta t=0.05 \mathrm{sec}$ is very sufficient for the present problem.

\section{RESULTS AND DISCUSSION}

Published experimental data are not available for the cavity configuration and boundary conditions similar to that taken in the present study. Thus, the validation of the computations against suitable experimental data could not be performed. However, in order to validate the predictive capability and accuracy of the present code, five published works have been chosen. For validation purpose of mixed convection flow and heat transfer, a differentially heated square cavity of natural laminar heat transfer is considered. The left surface is heated isothermally and right surface is cooled to a lower temperature with top and the bottom walls maintained thermally insulated. Average Nusselt number is calculated and depicted in Table (1) for $R a=100$ and compared with the earlier investigations [23-27]. From Table (1), it is clearly revealed that the agreement between the present and the previous results is very good indeed. So, these results provide great confidence to the accuracy of the present numerical method.

Table (1): Comparison of Average Nusselt number with Previous Workers for $R a=100$.

\begin{tabular}{|c|c|}
\hline Authors & $N u$ \\
\hline Saeid and Pop [23] & 3.002 \\
\hline Baytas [24] & 3.160 \\
\hline Bejan [25] & 4.200 \\
\hline Walker and Homsy [26] & 3.097 \\
\hline Present result & 3.076 \\
\hline
\end{tabular}

In the present investigation, Soda Lime glass beads saturated with distilled water is chosen as a porous media. Its permeability and porosity are taken as $1.57 \times 10^{-9}$ and 0.418 respectively. The controlling parameters on the heat transfer and fluid flow for this investigation are the hydrostatic pressure head and the constant heat flux. The computations have been carried out for the pressure head of $\Delta h=5,10,15$, 20 , and $30 \mathrm{~mm}$. The constant heat flux is varied in the range from 50 to $750 \mathrm{~W} / \mathrm{m}^{2}$.

Figure (2) shows the pressure distribution for different values of pressure head for a fixed value of heat flux $\left(100 \mathrm{~W} / \mathrm{m}^{2}\right)$. The pressure distribution is not affected by heat flux variation in spite of temperature appearance in Eq. (13). It is influenced by the pressure head variation in proportional form, i.e. the hydrostatic pressure at certain location increases with pressure head increasing. This is due to the increasing of the pressure value at the bottom and consequently alter the pressure distribution in the enclosure.

The temperature distribution for different pressure head values and a fixed value of $100 \mathrm{~W} / \mathrm{m}^{2}$ heat flux is displayed in Fig. (3). Figure (3) depicts that the temperature field is not strongly influenced by pressure head variation, but the pressure head increasing decreases the time required to reach a temperature of $90^{\circ} \mathrm{C}$ at the bottom enclosure wall. As mentioned above, increasing the pressure head leads to an increase in the pressure field which tends to increase the fluid velocity and then decreasing the consumed time for reaching a desired temperature. This behavior is clearly shown in Figs. (4) and (5). In these two figures, the temperature contours are illustrated for different time steps and for two pressure head values of $\Delta h=5 \mathrm{~mm}$ and $\Delta h=10 \mathrm{~mm}$. It is clearly depicted that for the same time step, the temperature at the bottom wall of the enclosure is higher with increasing pressure head and 


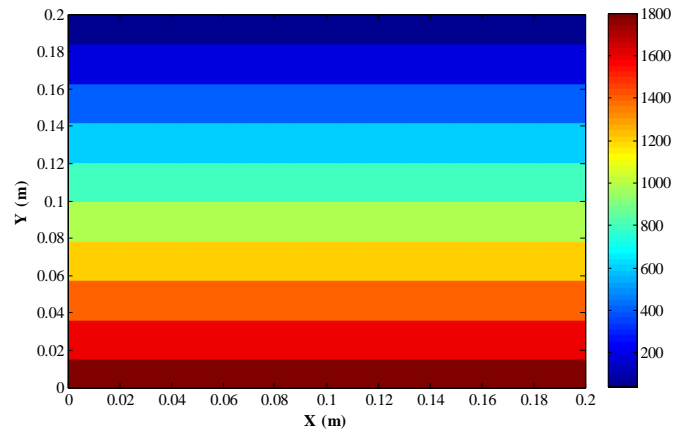

(a)

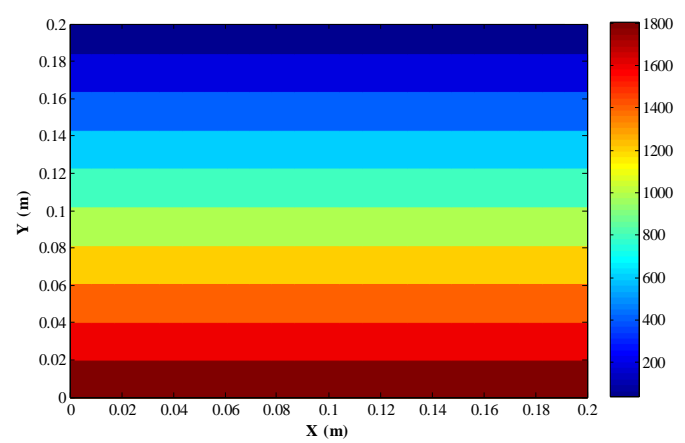

(b)

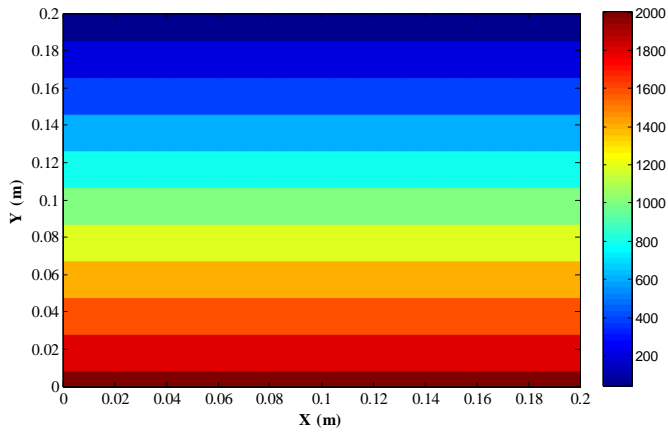

(c)

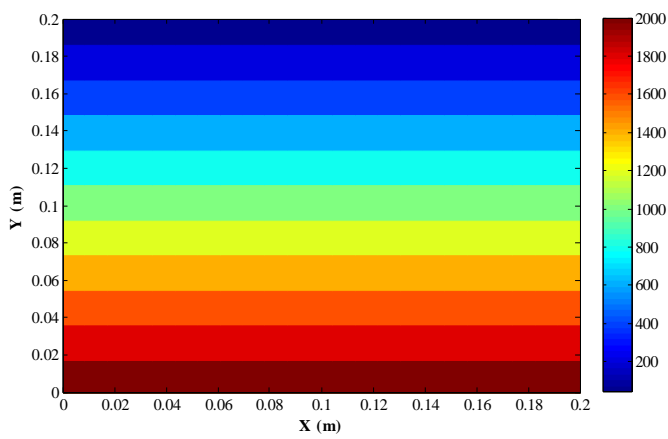

(d)

Figure (2): Pressure distribution for different pressure head with heat flux of $100 \mathrm{~W} / \mathrm{m}^{2}$. (a) $\Delta h=5 \mathrm{~mm}$, (b) $\Delta h=10 \mathrm{~mm}$, (c) $\Delta h=20 \mathrm{~mm}$, (d) $\Delta h=30 \mathrm{~mm}$.

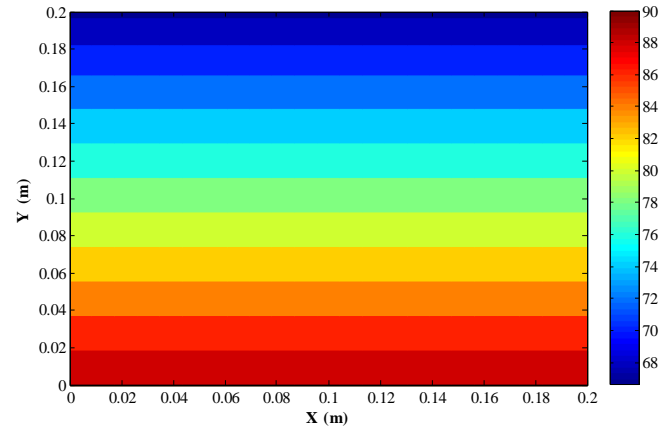

(a)

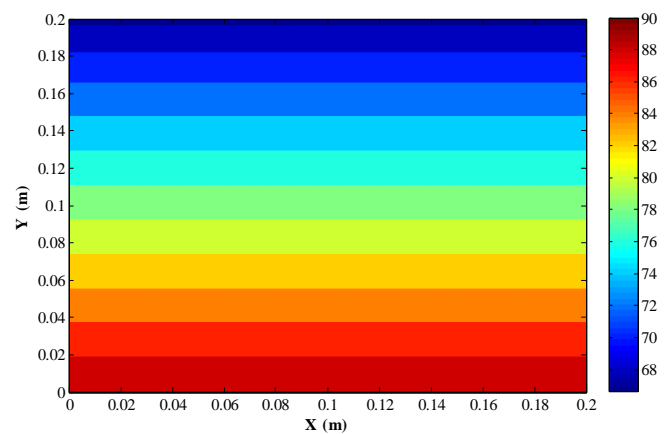

(b)

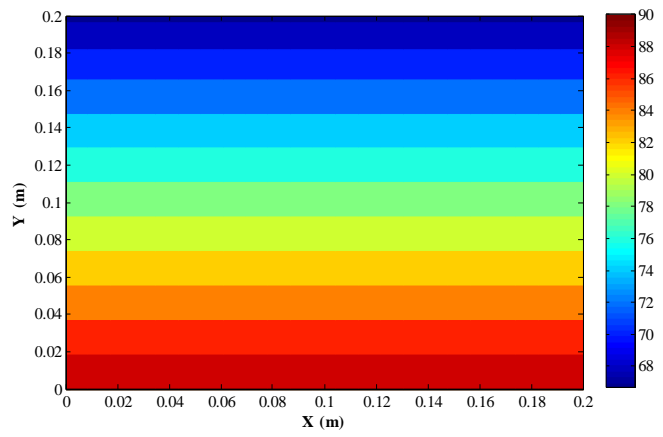

(c)

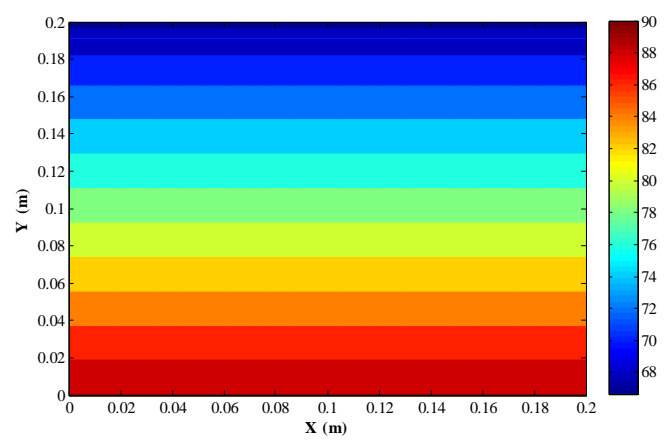

(d)

Figure (3): Temperature contours for different pressure head with heat flux of $100 \mathrm{~W} / \mathrm{m}^{2}$. (a) $\Delta h=5 \mathrm{~mm},(\mathrm{~b}) \Delta \mathrm{h}=10 \mathrm{~mm}$, (c) $\Delta h=20 \mathrm{~mm}$, (d) $\Delta h=30 \mathrm{~mm}$. 
the remaining locations has higher temperature also. This is because the mixed convection currents are increasing with pressure head and hence fluid velocity increases which accelerates the transfer of heat through the porous medium. It is noticed that the contours are all of parallel horizontal lines

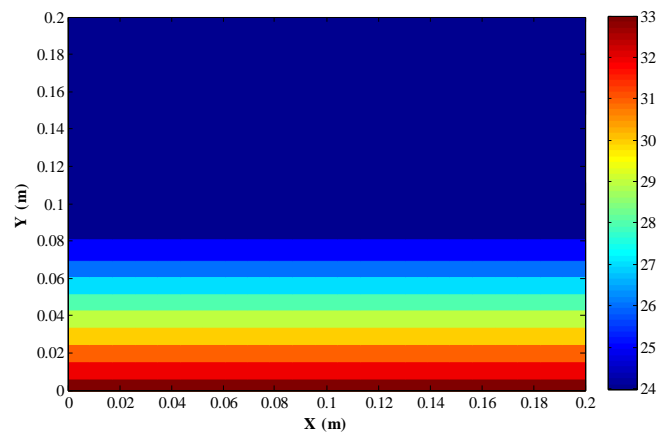

(a)

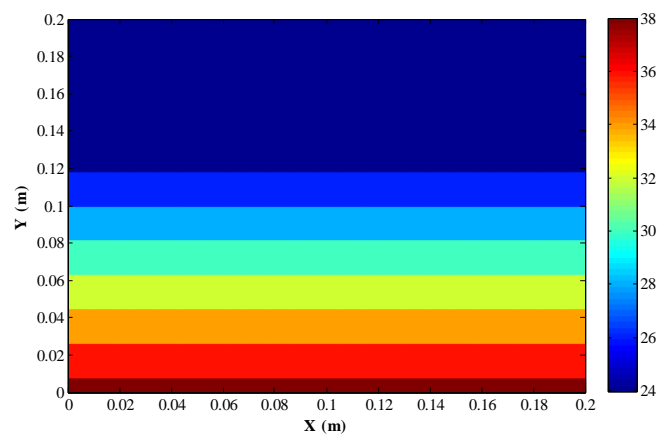

(b) which are resulted from the bottom wall heating of the enclosure and the induced pressure at the same wall also. Besides, when desired temperature is reached, the temperature contours are the same in Figs. (4) and (5) which indicates that these contours are not influenced by pressure head.

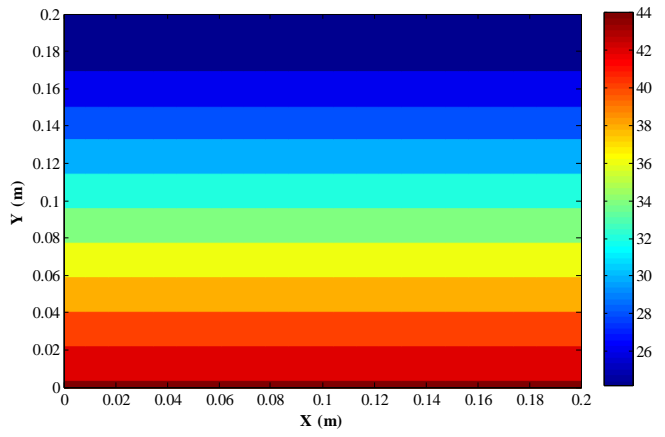

(c)

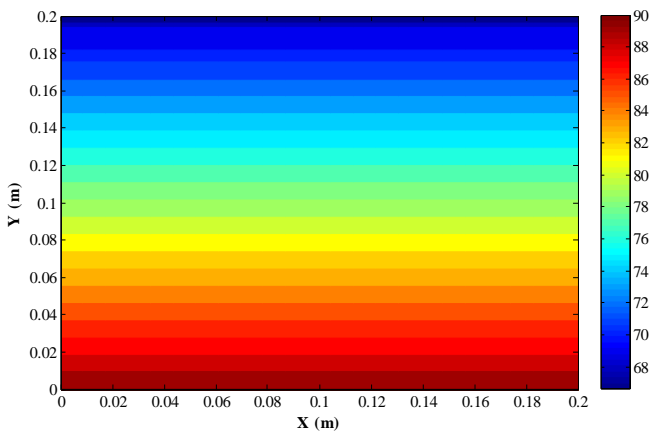

(d)

Figure (4): Temperature contours for different time steps with heat flux of $100 \mathrm{~W} / \mathrm{m}^{2}$ and $\Delta \mathrm{h}=5 \mathrm{~mm}$. (a) time $=100 \mathrm{sec}$, (b) time $=150 \mathrm{sec}$, (c) time $=200 \mathrm{sec}$, (d) time at $\mathrm{T}=90^{\circ} \mathrm{C}$.

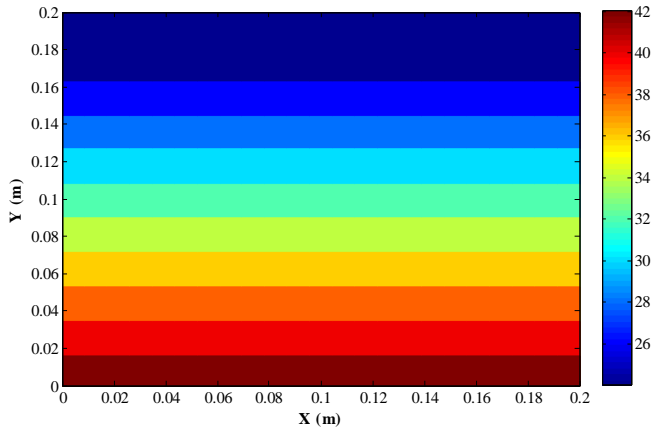

(a)

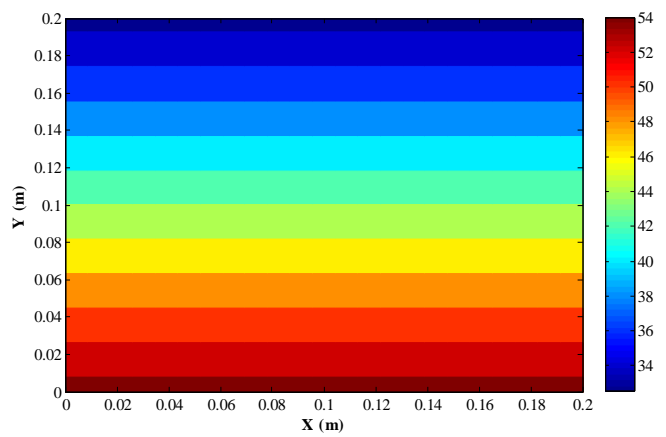

(b)

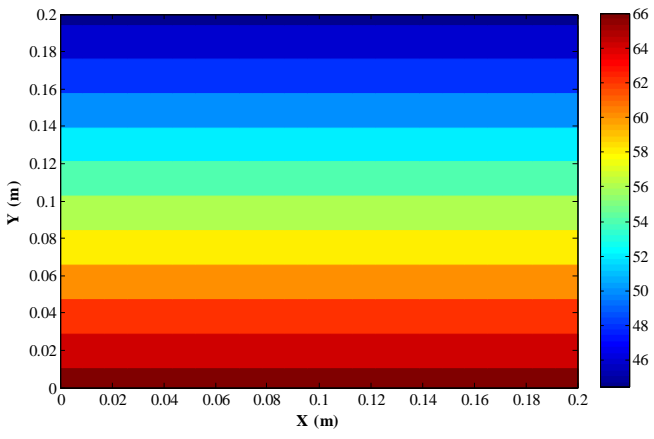

(c)

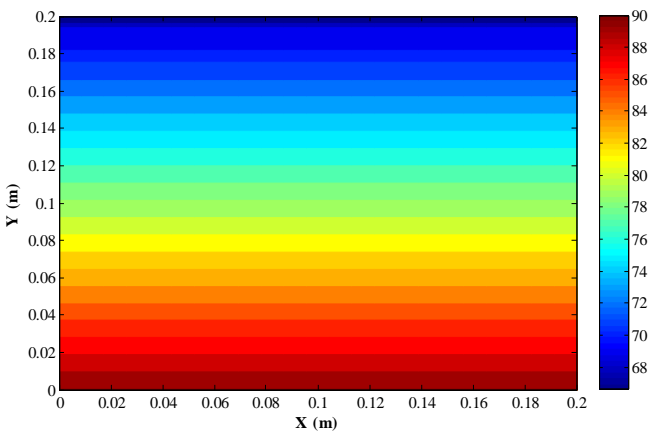

(d)

Figure (5): Temperature contours for different time steps with heat flux of $100 \mathrm{~W} / \mathrm{m}^{2}$ and $\Delta \mathrm{h}=10 \mathrm{~mm}$. (a) time $=100 \mathrm{sec}$, (b) time $=150 \mathrm{sec}$, (c) time $=200 \mathrm{sec}$, (d) time at $\mathrm{T}=90^{\circ} \mathrm{C}$ 
The velocity vectors for the flow of liquid is presented in Fig. (6) for different hydrostatic heads. Figure (6) shows that the magnitude of the liquid velocity vectors flow upward vertically and increased with the increase of the hydrostatic head. As the hydrostatic pressure head is increased, the pressure gradient in the $y$ direction is increased and as a result

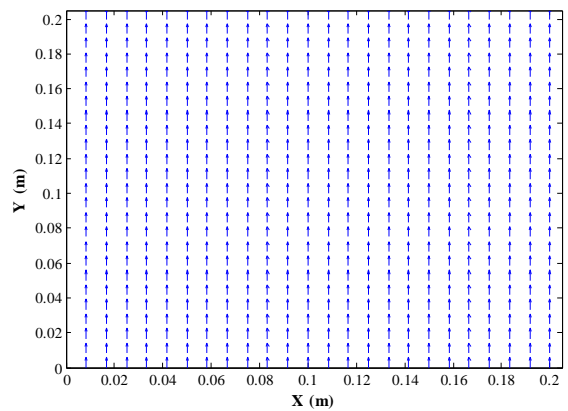

(a) $|\vec{V}|=0.0016 \mathrm{~m} / \mathrm{s}$

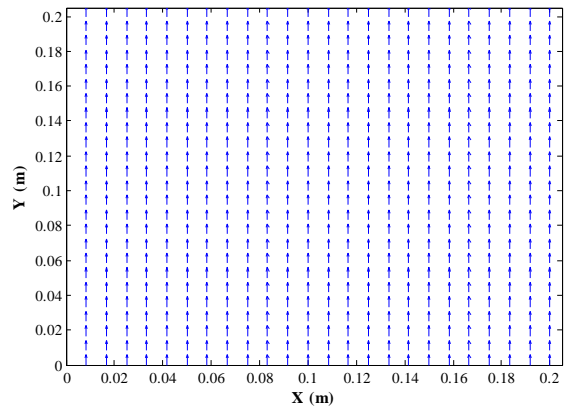

(b) $|\vec{V}|=0.0024 \mathrm{~m} / \mathrm{s}$ the velocity increases proportionally according to Eq. (3). The pressure head effect is larger than the heat flux variation effect on the velocity vector increasing, because the buoyancy forces induced from the temperature difference have smaller influence than that of head difference.

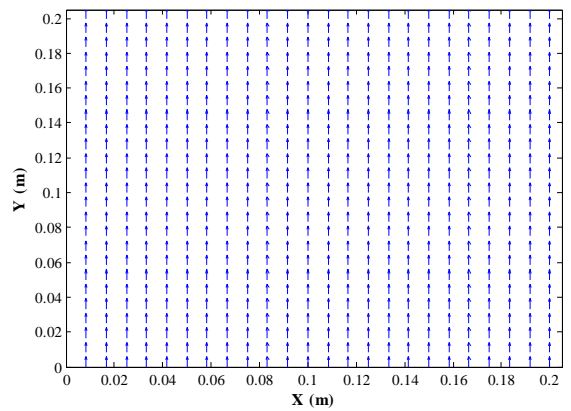

(c) $|\vec{V}|=0.004 \mathrm{~m} / \mathrm{s}$

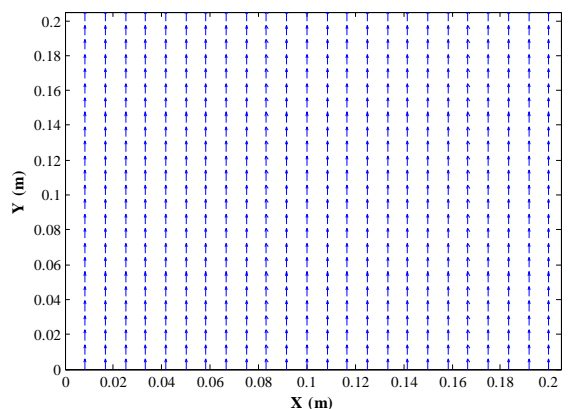

(d) $|\vec{V}|=0.0055 \mathrm{~m} / \mathrm{s}$

Figure (6): Velocity Vectors for different pressure head values and heat flux $q=100 \mathrm{~W} / \mathrm{m}^{2}$ when reaching $T=90^{\circ} \mathrm{C}$. (a) $\Delta h=5 \mathrm{~mm}$, (b) $\Delta h=10 \mathrm{~mm}$, (c) $\Delta h=20 \mathrm{~mm}$, (d) $\Delta h=30 \mathrm{~mm}$.

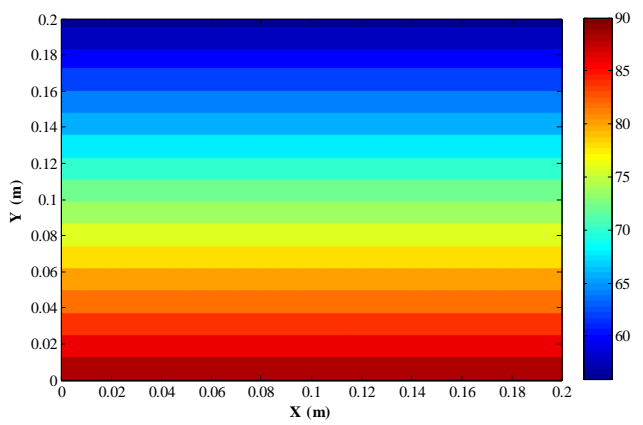

(a)

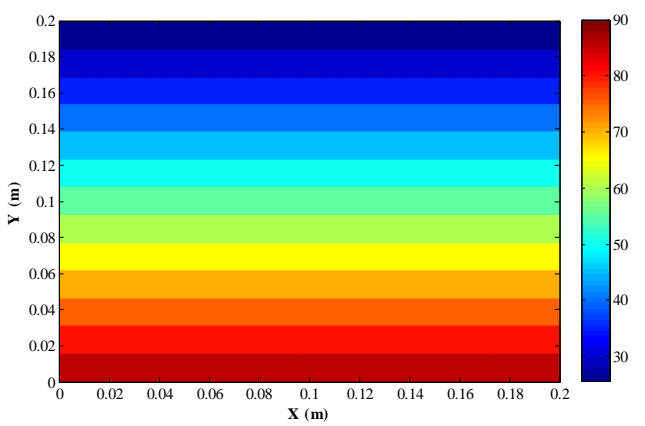

(b)

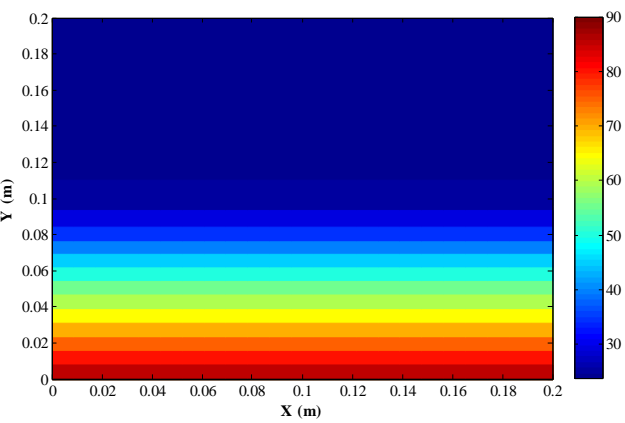

(c)

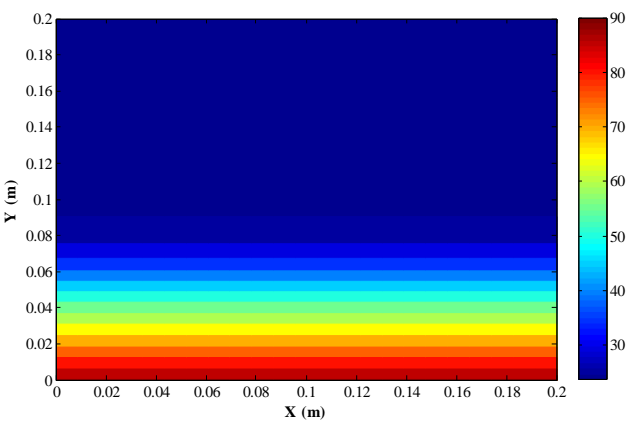

(d)

Figure (7): Temperature contours for different heat flux values and pressure head $\Delta h=20 \mathrm{~mm}$ when reaching $T=90^{\circ} \mathrm{C}$. (a) $150 \mathrm{~W} / \mathrm{m}^{2}$, (b) $300 \mathrm{~W} / \mathrm{m}^{2}$, (c) $600 \mathrm{~W} / \mathrm{m}^{2}$, (d) $700 \mathrm{~W} / \mathrm{m}^{2}$ 
The isotherms for different values of heat flux subjected to the enclosure bottom wall at certain pressure head are shown in Fig. (7). The isotherms show that the space occupied by the $90^{\circ} \mathrm{C}$ decreases with increasing heat flux amount. Additionally, the region that is near the top wall which lose heat by natural convection to the environment has lower temperatures as the heat flux increases. As the heat flux increases, i.e. the temperature gradient, the amount of energy conducted to the nearby regions increases at the same time period which results in faster increase in bottom temperature and reaching the desired value faster. As a result, smaller amount of energy is conducted to the top wall region and consequently its temperature becomes lower with the increase of the heat flux. The behavior of the time decreasing with heat flux increasing at certain pressure head value is illustrated clearly in Fig. (8). This is due to the increasing of the temperature gradient resulted from the heat flux increasing and hence the required temperature is reached faster. Also, the time required to reach the $90{ }^{\circ} \mathrm{C}$ temperature value is also decreased with the hydrostatic head increasing at fixed heat flux value because of the increasing convection currents that is invoked with the increasing of the pressure head and then

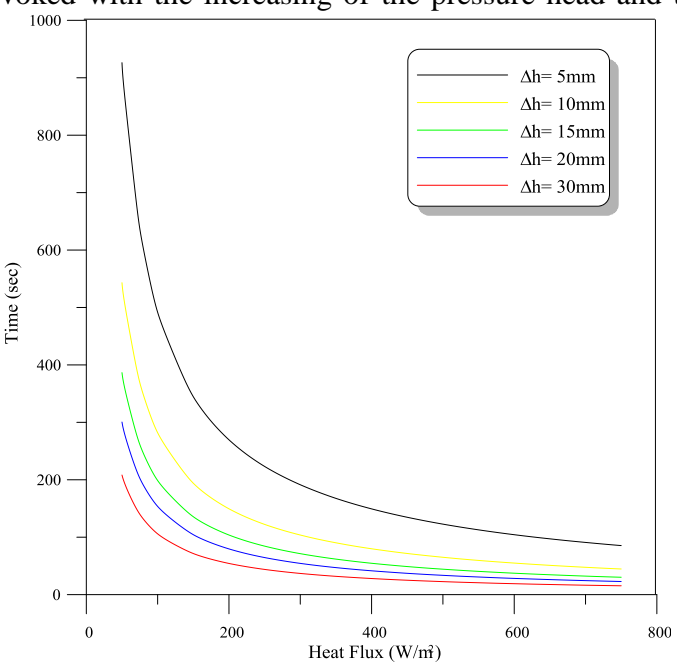

Figure (8): Time required to reach a temperature of $90{ }^{\circ} \mathrm{C}$ at certain heat flux value for different hydrostatic head values.

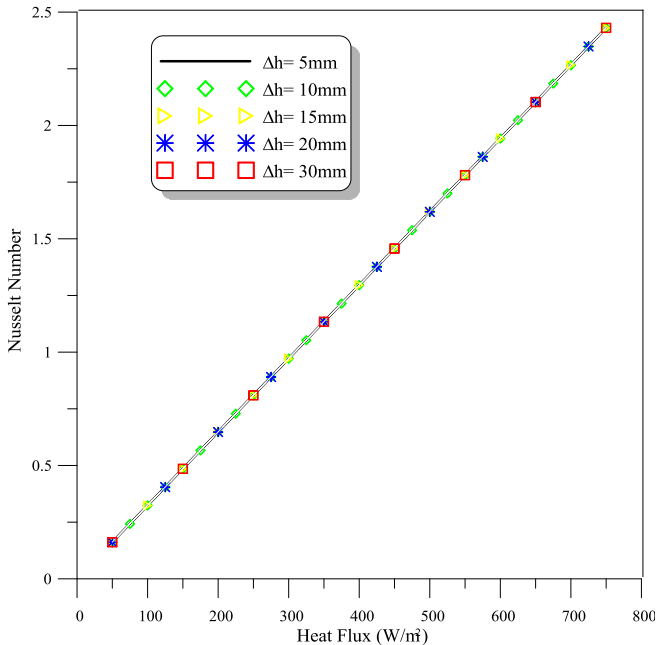

Figure (10): Nusselt number variation with heat flux for different hydrostatic pressure head at $T=90^{\circ} \mathrm{C}$. velocity fluid increasing. These convection currents plays a major role in transferring heat through the porous enclosure.

The average Nusselt number relation with time at the bottom heated wall for different heat flux values is displayed in Fig. (9). The Nusselt number decreases with the increasing time of simulation until reaching the desired $90{ }^{\circ} \mathrm{C}$ temperature. That is, the temperature gradient decreases with increasing time because the temperature increases with time due to the heat transfer between two locations and hence the temperature difference for these two locations becomes smaller. It is also observed that the same Nusselt Number values are obtained for different heat flux values but with smaller consuming time for reaching the desired temperature. Accordingly, the Nusselt number at the desired temperature needs larger time when heat flux subjected to the bottom wall increases, see Fig. (10). In this figure, the heat flux increasing cause the temperature gradient increase and thence the Nusselt number increase, see Eq. (14). Also, the pressure head variation does not make any variation on the Nusselt number at certain heat flux value.

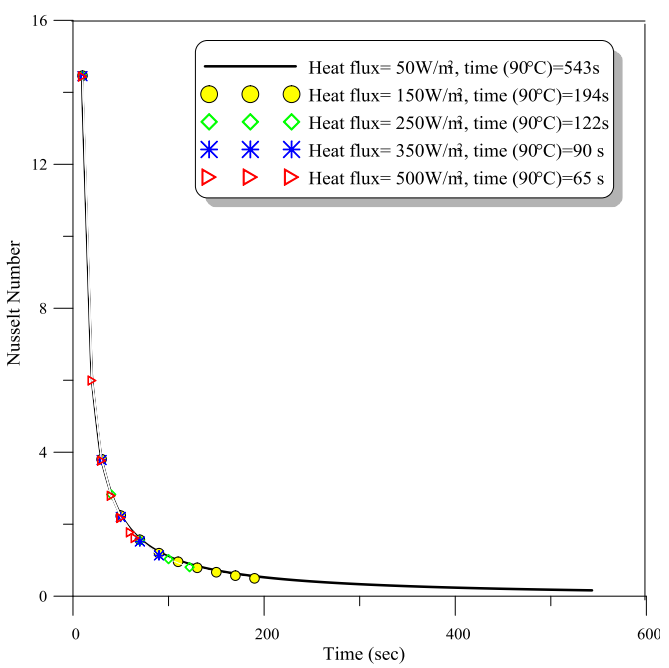

Figure (9): Nusselt number variation with time for different heat flux values.

\section{CONCLUSIONS}

Convective flow and heat transfer in a square porous cavity with constant heat flux at the bottom wall is investigated numerically. The following conclusions are made from this study.

- The pressure field and the velocity vector are increased with increasing hydrostatic pressure head.

- Time required for reaching a desired temperature is decreased with increasing heat flux and pressure head values.

- Increasing heat flux at certain pressure head leaves regions near the top cavity wall at lower temperature values.

- Increasing the hydrostatic pressure head does not affect the temperature field at the final state of reaching the desired temperature but affect it at earlier simulation time step.

- Average Nusselt number at the bottom heated wall is decreased with increasing time of simulation and it is increased proportionally with heat flux increasing. 


\section{REFERENCES}

[1] Wooding, R. A., 1960, "Rayleigh of a Thermal Layer in Flow Through a Porous Medium", J. Fluid Mech., vol. 9, 183-192.

[2] Wooding, R. A., 1963, "Convection in a Saturated Porous Medium at Large Rayleigh Number or Peclet Number", J. Fluid Mech., vol. 15, 527-544.

[3] Khanafer, K. M., and Chamkha, A. J., 1999, "Mixed Convection Flow in a Lid-Driven Enclosure Filled with a Fluid-Saturated Porous Medium", Inter. J. Heat and Mass Transfer, vol. 42, 2465-2481.

[4] Al-Amiri, A. M., 2000. "Analysis of Momentum and Energy Transfer in a Lid-Driven Cavity Filled with a Fluid-Saturated Porous Medium", Inter. J. Heat and Mass Transfer, Vol. 43, 3513-3527.

[5] Kandaswamy, P., Muthtamilselvan, M., and Lee, J., 2008, "Prandtle Number Effects on Mixed Convection in LidDriven Porous Cavity", J. Porous Media, Vol. 11, 791801.

[6] Khanafer, K. M., and Vafai, K., 2002. "Double-Diffusive Mixed Convection in a Lid-Driven Enclosure Filled with a Fluid-Saturated Porous Medium", Numer. Heat Transfer, Part A, Vol. 42, 465-486.

[7] Oztop, H. F., 2006, "Combined Heat Transfer in a Porous Lid-Driven Enclosure due to Heater with Finite Length", Int. Commun. Heat Mass Transf., Vol. 33, 772-779.

[8] Chai, Z., Guo, Z., and Shi, B., 2007, "Lattice Boltzmann Simulation of Mixed Convection in a Driven Cavity Packed with Porous Medium", Computational ScienceICCS 2007, Lecture Notes in Computer Science, Vol. 4487, 802-809.

[9] Vishnuvardhanarao, E., and Das, M. K., 2008, "Laminar Mixed Convection in a Parallel Two-Sided Lid-Driven Diffrentially Heated Square Cavity Filled with FluidSaturated Porous Medium", Numer. Heat Transfer, Part A, Vol. 53, 83-110.

[10] Kumar, D. S., Dass, A. K., and Dewan, A., 2009, "Analysis of Non-Darcy Models for Mixed Convection in a Porous Cavity Using a Multigrid Approach", Numer. Heat Transfer, Part A, Vol. 56, 685-708.

[11] Muthtamilselvan, M., 2011, "Forced Convection in a Two-Sided Lid-Driven Cavity Filled with Volumetrically Heat-Generating Porous Medium", Int. J. Appl. Math. And Mech., Vol. 7, No. 13, 1-16.

[12] Kumari, M., and Nath, G., 2011, "Steady Mixed Convection Flow in a Lid-Driven Square Enclosure Filled with a Non-Darcy Fluid-Saturated Porous Medium with Internal Heat Generation", J. Porous Media, Vol. 14, No. 10, 893-905.

[13] Waheed, M. A., Odewole, G. A., and Alagbe, S. O., 2011, "Steady Mixed Convective Heat Transfer in Rectangular Enclosures Filled with Porous Medium",
ARPN J. Eng. and Applied Sciences, Vol. 6, No. 8, 4760.

[14] Oztop, H. F., 2012, "Mixed Convection in Partially Cooled Lid-Driven Cavity Filled with a Non-Darcy Porous Medium", Progress in Computational Fluid Dynamics, Vol. 12, No. 1, 46-55.

[15] Mahmud, S., and Pop, I., 2006, "Mixed Convection in a Square Vented Enclosure Filled with a Porous Medium", Inter. J. Heat and Mass Transfer, Vol. 49, 2190-2206.

[16] Ghazanfarian, J., and Abbassi, A., 2007, "Mixed Convection in a Square Cavity Filled with a Porous Medium and Different Exit Port Position", J. Porous Media, Vol. 10, No. 7, 701-718.

[17] Bhuiyan, A. A., Barna, S. F., Banna, M. H., and Sadrul Islam, A. K. M., 2008, "Numerical Analysis on Mixed Convection through an Adiabatic Enclosure Filled with Fluid Saturated Porous Medium", Proceedings of the $4^{\text {th }}$ BSME-ASME Int. Conf. on Thermal Engineering, Dhaka, Bangladesh, 27-29.

[18] Chung, S., and Vafai, K., 2010, "Vibration Induced Mixed Convection in an Open-Ended Obstructed Cavity", Inter. J. Heat and Mass Transfer, Vol. 53, 27032714.

[19] Kumar, B. V., and Murthy, S.V.S.S.N.V.G. K., 2010 "Mixed Convection in a Non-Darcian Fluid Saturated Square Porous Enclosure Under Multiple Suction Effect", Inter. J. Heat and Mass Transfer, Vol. 53, 57645773.

[20] Hadley, G. R., 1986, "Thermal Conductivity of Packed Metal Powder", Inter. J. Heat and Mass Transfer, Vol. 29, No. 6, pp. 909-920.

[21] Suresh, Ch. S. Y., Vamsee Kriskna, Y., Sundararajan, T., and Das, S. K., 2005, "Numerical Simulation of ThreeDimensional Natural Convection Inside a Heat Generating Anisotropic Porous Medium", Heat Mass Transfer, Vol. 41, pp. 799-809.

[22] Versteeg H. K., and Malalasekera, W., 2007, "An Introduction to Computational Fluid Dynamics: The Finite Volume Method", $2^{\text {nd }}$ Edition, Pearson Education Limited Prentice Hall, England.

[23] Saeid, N. H., and Pop, I., 2004, "Transient Free Convection in a Square Cavity Filled with a Porous Medium", Int. J. Heat Mass Transfer, Vol. 47, pp. 1917 1924.

[24] Baytas, A. C., 2000, "Entropy Generation for Natural Convection in an Inclined Porous Cavity", Int. J. Heat Mass Transfer, Vol. 43, pp. 2089-2099.

[25] Bejan, A., 1979, "On the Boundary Layer Regime in a Vertical Enclosure Filled with a Porous Medium", Lett. Heat Mass Transfer, Vol. 6, pp. 93-102.

[26] Walker, K. L., and Homsy, G. M., 1978, "Convection in a Porous Cavity", J. Fluid Mech. Vol. 87, pp. 449-474. 